\author{
SERIES 'LUNG HYPERINFLATION IN AIRWAY OBSTRUCTION' \\ Edited by V. Brusasco and J.W. Fitting \\ Number 1 in this Series
}

\title{
Pulmonary hyperinflation a clinical overview
}

\author{
G.J. Gibson
}

\begin{abstract}
Pulmonary hyperinflation a clinical overview. G.J. Gibson. @ ERS Journals Ltd 1996. ABSTRACT: Pulmonary hyperinflation is usually defined as an abnormal increase in functional residual capacity, i.e. lung volume at the end of tidal expiration. As such, it is virtually universal in patients with symptomatic diffuse airway obstruction. Hyperinflation inferred from a standard chest radiograph implies an increase in total lung capacity.

The relaxation volume of the respiratory system $\left(V_{r}\right)$ increases in patients with chronic airway disease as a result of changes in the elastic properties of the lungs and chest wall. In addition, a variable degree of dynamic hyperinflation may be present. This results from the onset of inspiration before lung volume has fallen to $V \mathrm{r}$. Dynamic hyperinflation is frequently present at rest in patients with moderate-to-severe airway obstruction, and it increases further on exercise, thereby increasing the mechanical load on the inspiratory muscles and at the same time reducing their mechanical advantage.

Important clinical consequences and associations of hyperinflation include: distortions of chest wall motion; impaired inspiratory muscle function; increased oxygen cost of breathing; greater likelihood of hypercapnia; impaired exercise performance; and greater severity of breathlessness. The symptomatic improvement after treatment with a bronchodilator may be due, in part, to lessening of hyperinflation.
\end{abstract}

Eur Respir J., 1996, 9, 2640-2649.

\section{Definitions}

To the radiologist, hyperinflation of the lungs implies an increase in total lung capacity (TLC), as this is the lung volume at which chest radiographs are normally obtained. In a clinical context, however, hyperinflation implies an abnormal increase in the volume of gas in the lungs at the end of tidal expiration. For the purpose of this review, this end-expiratory lung volume (sometimes abbreviated as EELV) is regarded as the functional residual capacity (FRC). It should be noted that some authors reserve use of the term FRC for the true neutral or relaxation volume $(V \mathrm{r})$ of the respiratory system. where inward lung recoil is balanced by outward chest wall recoil. In patients with airway obstruction and hyperinflation, FRC often exceeds $V_{\mathrm{r}}$ because of the phenomenon of "dynamic hyperinflation", i.e. the situation where tidal inspiration begins before expiration to $V_{\mathrm{r}}$ is complete (see below).

Sometimes, hyperinflation is inferred from an increase in residual volume (RV), or in the ratio of RV to total lung capacity (TLC), a feature otherwise known as air-trapping. An increase in RV is virtually always accompanied by an increased FRC, but an increased $\mathrm{RV} / \mathrm{TLC}$ (or FRC/TLC) ratio is less specific as it may occur due to a reduced TLC as well as to an increased RV.

Another relevant volume is the end-inspiratory lung volume (EILV). During exercise in patients with hyperinflation, this may approach TLC and may have important implications for exercise capacity and dyspnoea (see below).

\author{
Correspondence: G.J. Gibson \\ Dept of Respiratory Medicine \\ Freeman Hospital \\ Newcastle upon Tyne \\ NE7 7DN \\ UK
}

\section{Keywords: Asthma}

breathlessness

chronic obstructive pulmonary disease

emphysema

hyperinflation

\section{Received: July 31996}

Accepted for publication September 51996
Hyperinflation occasionally occurs in patients with conditions other than airway obstruction if the RV is increased by some other mechanism. Examples include patients with expiratory muscle weakness or mitral valve disease. For practical purposes, however, hyperinflation relates essentially to patients with generalized airway narrowing, as in chronic obstructive pulmonary disease (COPD) and emphysema, asthma, bronchiectasis and cystic fibrosis.

\section{Radiographic and physical features}

Because, conventionally, chest radiographs are obtained at TLC, the radiographic impression may underestimate the severity of hyperinflation during tidal breathing. Radiographically, hyperinflation is manifest by depression of the diaphragm, a loss of its normal curvature, and an increase in the retrosternal airspace (fig. 1). The diaphragmatic attachments to the lower ribs are not normally visible on plain chest radiography, but are exposed when the diaphragm is depressed, giving the costophrenic angles a blunted appearance (fig. 2).

In clinical practice, the radiographic assessment of hyperinflation is usually subjective, but specific quantitative indices are sometimes applied. Thus, the diaphragm is low if the level of the right dome is at or below the anterior end of the 7th rib, and it is flat if the maximum curvature of the dome is less than $1.5 \mathrm{~cm}$ [1]. The width of the retrosternal space can be measured on the lateral projection, as the horizontal distance from the posterior aspect of the sternum $3 \mathrm{~cm}$ below the sternomanubrial 
a)

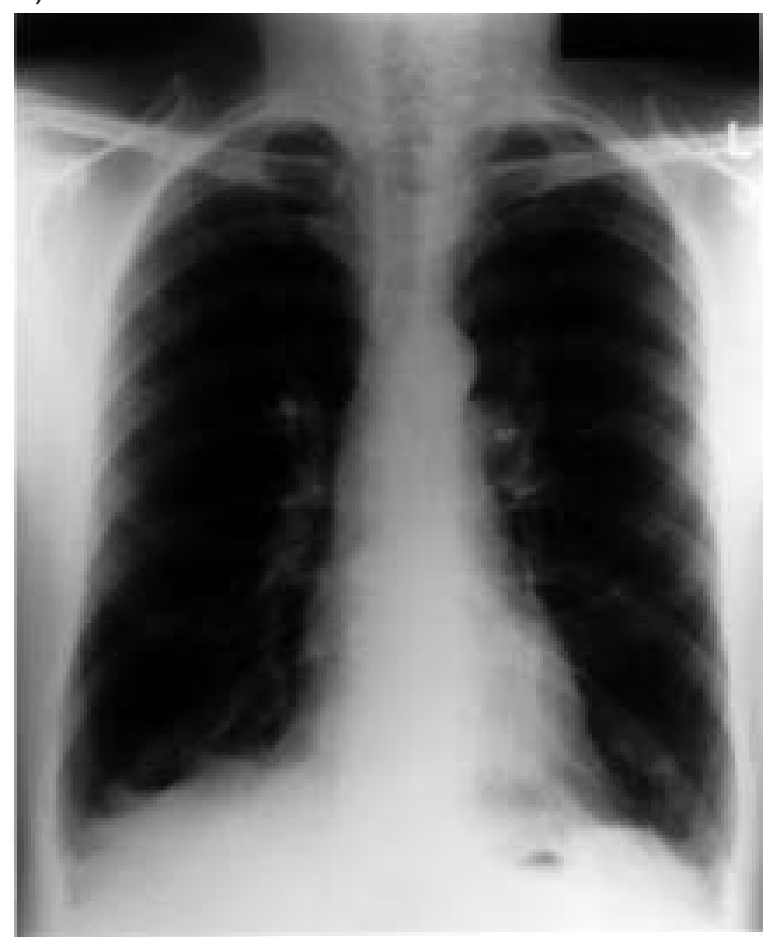

b)

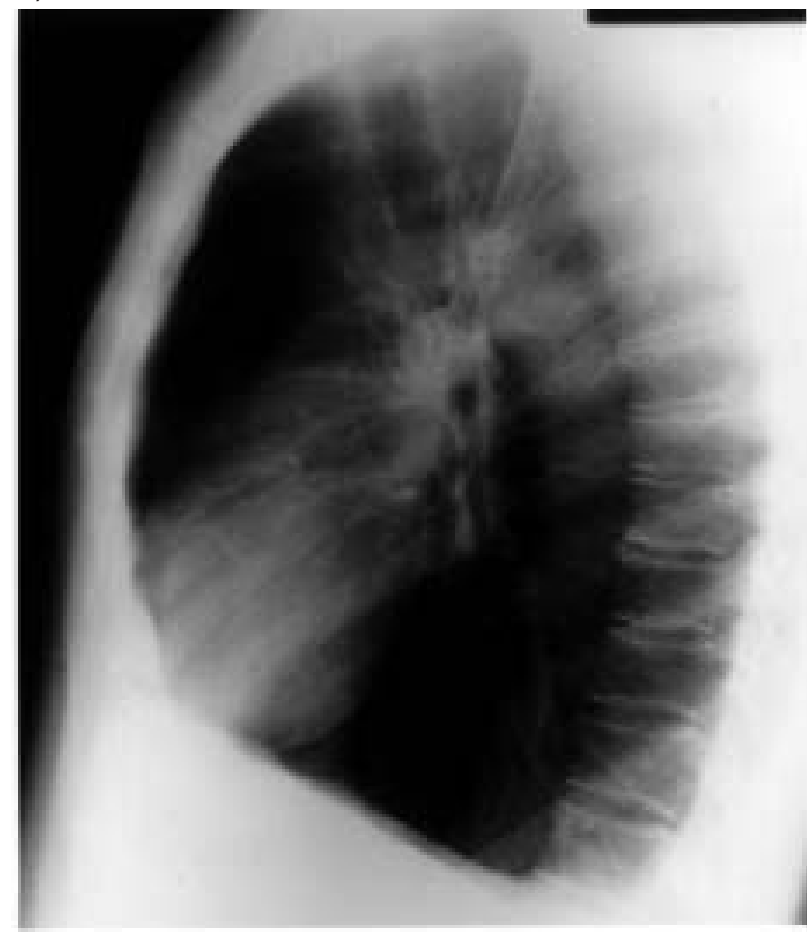

Fig. 1. - a) Posteroanterior (PA); and b) lateral chest radiograph taken at total lung capacity (TLC) and showing hyperinflation.

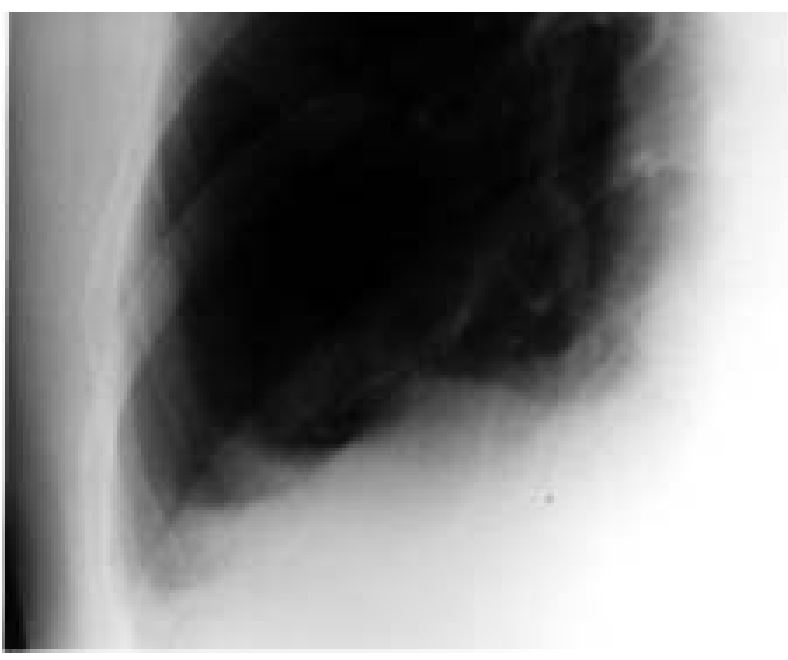

Fig. 2. - Close up of posteroanterior (PA) chest radiograph at full inflation in a patient with hyperinflation, showing costal attachments of the diaphragm. These are not usually visible in normal subjects.

junction to the anterior margin of the aorta. The precise range of normality is uncertain, with suggested upper limits ranging $2.5-4.5 \mathrm{~cm}$. The larger distance is more specific for hyperinflation and values greater than this are associated with very severe airway obstruction [2].

In routine radiological reporting, hyperinflation is sometimes incorrectly equated with emphysema, but other more specific features, such as the presence of bullae or attenuation of vessels, are required for confident recognition of this condition.

In principle, hyperinflation of the lungs can be accommodated by a varying combination of increased rib cage size and lowered diaphragm. The classic sign of rib cage expansion is the so-called "barrel chest" deformity, which has long been described as a sign of "emphysema" [3]. Direct measurements of rib cage dimensions, however, have produced conflicting results: KILBURN and ASMUNDSSON [4], studying a group of unselected patients with "emphysema", found that the anteroposterior (AP) dimension of the rib cage measured with calipers at full inflation was not different from measurements in control subjects. They suggested that the impression of increased AP diameter of the chest was actually the result of a reduced AP diameter of the abdomen, due to wasting. On the other hand, Gilmartin and Gibson [5] measured the dimensions of the rib cage at FRC and showed an increase in the ratio of AP to lateral diameters, i.e. the rib cage was more circular in cross-section than in normal subjects. This discrepancy may be due to the different volumes at which the two studies were performed, since a greater relative difference compared with normal subjects would be expected at FRC than at TLC.

The few available radiographic measurements of rib cage dimensions in COPD are also difficult to reconcile. Burki and KRUMPELman [6] showed clear correlations of TLC with both the width of the retrosternal space and the height of the diaphragm. SHarp et al. [7], however, measured the angulation of the ribs on the lateral chest radiograph and showed that only 5 of 12 subjects accommodated the increased volume by elevating the rib cage, while the others had lower diaphragmatic position. In a subsequent study of 22 patients with COPD, the same group [8], surprisingly, showed no significant differences from normal either in the dimensions of the rib cage or the rib angles, with all the increased volume apparently accommodated by diaphragmatic descent. The authors suggested that the radiographic impression 
of increased retrosternal airspace is simply a consequence of diaphragmatic descent and that the apparent increase in AP diameter is illusory. The level of the rib cage at which the measurements are made may be critical to the interpretation, as in acutely induced asthma an increase in the AP diameter of the upper rib cage at (the elevated) FRC has been reported [9], while changes in the AP diameter of the lower rib cage were less pronounced.

Hyperinflation results in abnormal distribution of resting tidal breathing between the rib cage and abdominal compartments. In addition, distortions of chest wall motion are frequently present. In general, the greater the FRC the less the AP motion of the abdomen during tidal inspiration [5]. Although AP motion of the upper rib cage is generally preserved and may even be increased [9], presumably due to greater use of intercostal and accessory muscles, AP motion at the lower sternum and lateral motion of the rib cage are often distorted. The best recognized distortion is lateral inspiratory paradox of the rib margin, otherwise known as Hoover's sign [10]. In one study [5], this was detectable in as many as 31 of 40 otherwise unselected patients with COPD. Paradoxical lateral motion typically develops with the onset of inspiration, continuing to late inspiration, sometimes with an increase in the dimension in the terminal part of inspiration. The peak distortion corresponds both to the peak negative pleural pressure and the peak transdiaphragmatic pressure, and has been attributed to direct traction by the flattened diaphragm on the lateral rib margins [11].

AP paradox, seen typically at the lower end of the sternum, is less easy to recognize clinically, but it can be detected with the trained eye or by recording with devices such as magnetometers. This occurs in early inspiration and is unrelated to transdiaphragmatic pressure $(P \mathrm{di})$. Gilmartin and Gibson [11] showed that the maximum distortion in the AP direction was most closely related to the nadir of abdominal pressure in early inspiration, and they suggested that the paradoxical motion was due to relaxation of abdominal muscles which had contracted during the immediately preceding expiration. A similar pattern has been described with induced asthma [9], resulting in a "rocking" motion of the sternum during inspiration, with the lower part moving in as the upper part moves out. These observations emphasize the plasticity of the rib cage, which in conditions of hyperinflation can move with several degrees of freedom.

Paradoxical inspiratory motion of the abdominal wall has also been described in patients with COPD. This usually occurs in the presence of very severe disease during exacerbations [12].

\section{Mechanisms of hyperinflation}

The pathophysiological mechanisms of hyperinflation are discussed in detail in later reviews in this series. Summarized here are the similarities and possible differences between patients with asthma and those with COPD, which may be relevant to the clinical consequences in the different conditions. In normal subjects,
FRC, i.e. lung volume at end-tidal expiration, is very close to $V \mathrm{r}$, the relaxation volume of the respiratory system. In patients with airway obstruction, changes in the elastic properties of the lungs and chest wall lead to an increase in $V \mathrm{r}$, i.e. static hyperinflation. In addition, however, there is a variable degree of dynamic hyperinflation, reflected by an increase in FRC above Vr. In general, with increasing airway resistance and greater flow limitation, expiration towards $V \mathrm{r}$ becomes increasingly prolonged and the next inspiration begins before $V_{\mathrm{r}}$ is reached. This places an extra load on the inspiratory muscles at endexpiration: they have to overcome an additional "threshold" load related to the elastic recoil of the respiratory system before inspiratory flow commences. Furthermore, this occurs in the face of worsening mechanical advantage of the inspiratory muscles as dynamic hyperinflation increases. Dynamic hyperinflation is often present to some degree at rest and increases further on exercise (see below). It may also worsen acutely during exacerbations associated with increasing airway obstruction.

In COPD, electrophysiological studies suggest that the inspiratory muscles "switch off" early in expiration $[13,14]$, but in asthma it appears that tonic inspiratory muscle activity may remain throughout expiration and this may contribute to the hyperinflation, at least when asthma is induced acutely, e.g. with histamine or methacholine. Persistent inspiratory muscle activity will tend to slow expiratory flow, and may have the advantage of protecting diaphragmatic length and shape by increasing rib cage size and reducing the relative abdominal contribution to hyperinflation [15]. The persistent inspiratory activity has been inferred from electromyography [16], pleural pressure measurements [15] and measurement of external dimensions [9]. It is unclear at present whether such tonic inspiratory muscle activity during expiration is limited to transiently induced bronchoconstriction, or whether it also occurs in more prolonged asthmatic episodes.

\section{Respiratory muscle function}

Hyperinflation is accompanied by a reduced mechanical advantage of the inspiratory muscles and, consequently, maximum static inspiratory pressure $(P \mathrm{I}, \max )$ measured at RV or FRC is often less (strictly less negative) than in normal subjects at the same "relative" lung volumes, as originally reported by SHARP et al. [17]. However, ByRD and HyatT [18] showed that, in many patients with COPD, PI,max was actually greater (more negative) than would have been expected for the "absolute" lung volume (FRC) at which the measurements were made. Conventionally measured maximum respiratory pressures include a contribution from the passive recoil pressure of the respiratory system $(P \mathrm{pr}, \mathrm{rs})$, and later calculations by ROCHESTER et al. [19] showed that, after allowing for $P$ pr,rs and differences in lung volume, the pressure generated by the inspiratory muscles alone was usually similar to normal. In some patients with severe COPD, however, malnutrition may result in a true impairment of inspiratory muscle force.

Clearly, at lung volumes which exceed the normal TLC, adaptation of inspiratory muscle function to hyperinflation must occur, since normal subjects are 
unable to achieve such volumes. In this context, most attention has been paid to the diaphragm which, despite its severe mechanical disadvantage at high lung volumes, continues to generate an inspiratory pressure, as demonstrated both by forceful voluntary efforts [20], and phrenic nerve stimulation [21]. The possible mechanisms involved in this adaptation are discussed in a later review in this series [22].

\section{Lung volumes}

Elevation of FRC is an almost universal accompaniment of significant diffuse intrathoracic airway obstruction. It may fail to occur if there is coexistent disease, such as pulmonary fibrosis, which tends to reduce lung volumes. Overall, there is a general relationship between the severity of hyperinflation and that of airway narrowing. This has been demonstrated by the relationship between FEV1 and both RV/TLC [23] and FRC/ TLC [24] (fig. 3). This association complicates the attribution of various possible consequences to, on the one hand, the degree of airway narrowing and, on the other hand, the extent of hyperinflation.

In COPD, the greatest increases in TLC are usually seen in patients with the most severe emphysema, but the distinction is insufficiently reliable without other radiographic or functional evidence of emphysema.

Increases in TLC in asthma have been the subject of considerable interest and some dispute. In surveys or routine reporting of chest radiographs of patients with asthma, overinflation is frequently noted. It may be seen even without severe airway obstruction. In chronic asthma, radiographic overinflation is much more likely if the onset was in childhood. In this context, age of onset appears to be more important than duration of asthma [25]. A recent study [26] of function has supported this conclusion and suggested that the abnormality develops early in childhood. More controversial has been the

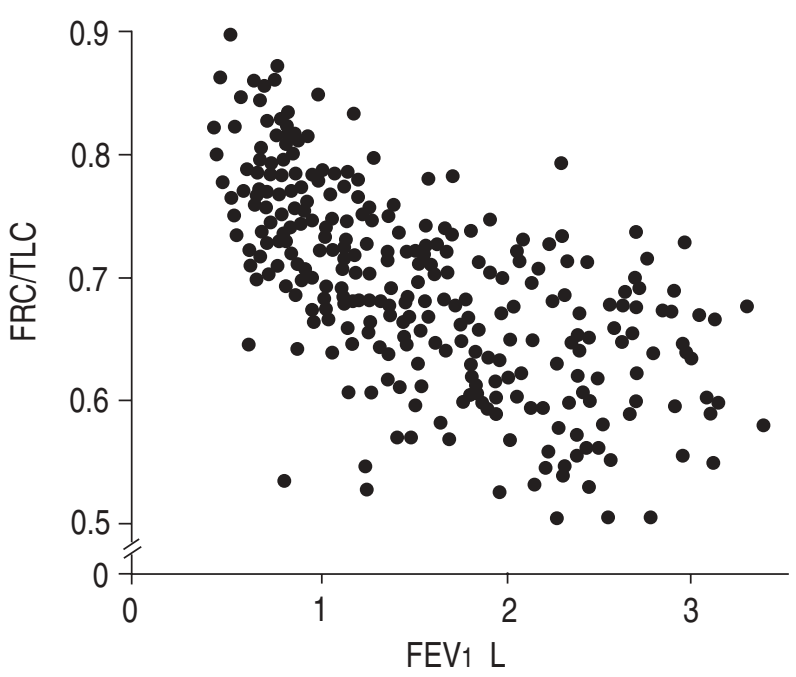

Fig. 3. - Inverse relationship of functional residual capacity/total lung capacity (FRC/TLC) to forced expiratory volume in one second $(\mathrm{FEV} 1)$ in 311 patients with chronic obstructive pulmonary disease (COPD). (Modified from BÉGIN and GRAssino [24]). question of apparently acute changes in TLC during and following exacerbations of asthma. This was first shown by WOOLCOCK and READ [27], who studied patients during recovery from asthmatic attacks. During several days of treatment, they showed the expected marked reductions in FRC and RV ( $3 \mathrm{~L}$ or more), but in addition, there was a fall in TLC in $50 \%$ of the patients studied. In this report, lung volumes were measured by helium dilution. In a subsequent study [28] based on plethysmographic measurements, the falls in FRC during recovery and the proportion of patients showing a reduction in TLC were even greater. Other studies suggested acute increases in TLC (measured plethysmographically) following exercise challenge [29, 30] and inhalation of histamine [31]. WoOLCOCK and co-workers [28] had originally acknowledged the possibility that plethysmographic volume measurement might be an overestimate if changes in mouth pressure did not correspond to changes in alveolar pressure. Later reports in the early $1980 \mathrm{~s}[32,33]$ showed this to be the case, casting considerable doubt on the validity of the acute changes in TLC reported up to that time. Errors in the plethysmographic technique are minimized by encouraging the subject to pant at a low frequency $(<1 \mathrm{~Hz})$, and by ensuring adequate support of the cheeks and floor of the mouth during panting in order to minimize volume changes of the compliant upper airway [34].

It now appears likely that many of the acute changes in TLC reported in the earlier literature were artefactual, or were at least exaggerated by the plethysmographic technique. Nevertheless, it is clear that true increases in total lung capacity can occur during spontaneous exacerbations. The shortest time scale over which TLC increases and subsequently decreases is uncertain, but it is probably a matter of days rather than hours or minutes. It should be recalled that the original study by WoOLCOCK and ReID [27] was performed using helium dilution and, therefore, the conclusion was not compromised by plethysmographic errors. In addition, two recent studies using radiographic measurements during recovery from spontaneous asthma have confirmed reductions in TLC averaging 0.29 and $0.7 \mathrm{~L}$, respectively $[35,36]$. The magnitude of these changes was not clearly correlated with increases in $\mathrm{FEV} 1$, but greater falls in TLC were seen as the interval between the exacerbation and the recovery radiograph increased [36]. However, with short-term provocation, e.g. with methacholine, it appears that TLC does not change significantly [37, 38].

Elevation of TLC is found in a significant proportion of patients with widespread bronchiectasis [39], and is probably simply a function of the severity of airway obstruction in a heterogeneous group of subjects. In cystic fibrosis, however, TLC is more often normal, despite the presence of severe airway obstruction $[40,41]$. This may represent a counterbalancing effect of fibrotic scarring in areas of recurrent infection. As would be expected, FRC is more consistently elevated [41]. Information on the consequences of hyperinflation for inspiratory muscle function in cystic fibrosis is conflicting, with some series [42] showing impairment, especially in more malnourished individuals, but the overall impression is of well-preserved inspiratory muscle function in most ambulant patients. 


\section{Cost of breathing and resting gas exchange}

It has been proposed that the increased work of breathing associated with airway obstruction and hyperinflation may contribute to the weight loss experienced by many patients with COPD. The oxygen cost of breathing is greater in malnourished patients than in those with normal nutrition [43] and, in general, malnourished patients have more hyperinflation (as assessed by RV/ TLC) and lower values of PI,max. Donahoe et al. [43] showed that the oxygen cost of breathing was most closely correlated with RV/TLC\%, but the interrelation between indices of hyperinflation and airway narrowing make confident attribution of the mechanism impossible. It has been shown that hypercapnic patients with COPD have a disproportionately high cost of breathing and this also correlates with evidence of hyperinflation, as assessed both by RV/TLC and radiographic diaphragmatic flattening [44]. In theory, distortions and paradoxical motion of the chest wall, which would reduce efficiency of breathing, might further increase oxygen consumption, but in one study [45] this appeared to make no significant contribution.

In a study of the interrelations between indices of gas exchange and mechanical function in a large number of patients with COPD, Burrows et al. [23] showed that the mixed venous carbon dioxide tension $\left(P_{\mathrm{v}}, \mathrm{CO}_{2}\right)$ measured by rebreathing was directly related to hyperinflation as assessed by RV/TLC, but again the strong inverse relationship between RV/TLC and FEV1 may account for the correlation. ROCHESTER and BRAUN [46] showed that arterial carbon dioxide tension $\left(\mathrm{Pa}, \mathrm{CO}_{2}\right)$ was inversely related to $P \mathrm{I}$,max (fig. 4 ), which in turn is related to the severity of hyperinflation. They also compared the implications of reduced $P \mathrm{I}$,max for gas exchange in patients with COPD and those with primary respiratory muscle weakness. As might be expected in view of their greater respiratory impedance, for a given $P \mathrm{I}$,max, $P \mathrm{a}, \mathrm{CO}_{2}$ was relatively higher in patients with COPD than in

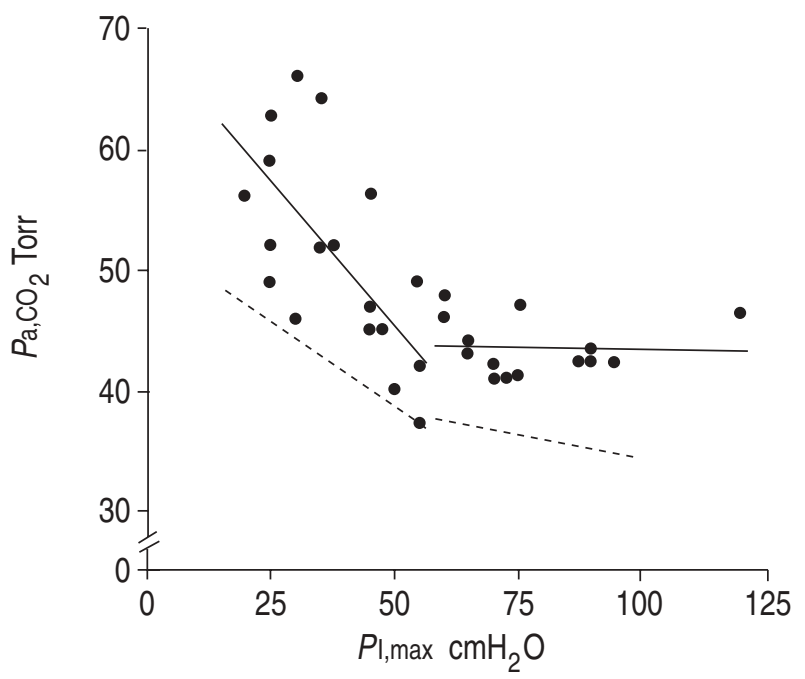

Fig. 4. - Relationship of arterial carbon dioxide tension $\left(P \mathrm{a}, \mathrm{CO}_{2}\right)$ to maximal inspiratory pressure $\left(P_{\mathrm{I}, \max }\right)$ in patients with chronic obstructive pulmonary disease (COPD) (symbols and solid lines) compared with similar relationship in patients with muscle weakness (broken line). ( 1 Torr $\approx 0.133 \mathrm{kPa}$ ). (Modified from Rochester and BRAun [46]). those with respiratory muscle weakness alone. Hypercapnia is also related to the degree of dynamic hyperinflation [10, 47], but interpretation is confounded by the severity of airway obstruction, as well as by uncertainty over the validity of estimates of dynamic hyperinflation. The results of BEGIN and GRASSINO [24] further support the importance of inspiratory muscle capacity, and hence the importance of hyperinflation, in determining the presence of hypercapnia. In a large number of patients with stable COPD, they showed that the best predictor of $\mathrm{Pa}, \mathrm{CO}_{2}$ among a number of variables was the ratio of the load to the capacity of the inspiratory muscles, as assessed by the ratio of pulmonary resistance to $P \mathrm{I}$,max.

\section{Sleep}

Careful measurements of lung volumes during sleep have been performed in small groups of patients with hyperinflation studied while sleeping supine in a volume displacement plethysmograph. BALLARD et al. [48] showed that, while the FRC of patients with mild asthma when awake was greater than control subjects, during sleep the fall in FRC exceeded that in normals, so that during rapid eye movement (REM) sleep FRC was similar in the two groups (fig. 5a). They suggested that, since the reduction of lung volume during sleep would inevitably be accompanied by an increase in airway resistance, it might contribute to nocturnal worsening of asthma. However, this seems unlikely as in a subsequent study [49], in which negative pressure was applied around the chest in order to maintain FRC, the fall in forced expiratory volume in one second (FEV1) following sleep was not prevented. In a further study [50], the same group showed that the reduction in FRC during sleep in asthma was accompanied by reduced tonic activity of the inspiratory muscles. On waking, there was a "rebound" increase in FRC to values greater than before sleep. This was associated with increased tonic and phasic inspiratory muscle activity, presumably as a consequence of the greater airway narrowing on waking. In a parallel study of patients with COPD [51], the same group showed no reduction in FRC during sleep (fig. 5b). This may reflect different mechanisms of hyperinflation in the two conditions, with persistent activity of inspiratory muscles in expiration contributing in asthma, but not in COPD.

One proposed mechanism for the well-recognized hypoxaemia during sleep (particularly REM sleep) in COPD was a reduction in FRC, but the failure to demonstrate such a fall negates this suggestion. WHITE et al. [52] further investigated whether distortions of chest wall movement, in particular worsening lateral paradox, might contribute to hypoxaemia during REM sleep. They hypothesized that reduction in activity of inspiratory muscles other than the diaphragm in REM sleep might lead to greater distortion, but in the event Hoover's sign during REM sleep became less evident, rather than more evident, presumably as a consequence of the reduced force of diaphragmatic contraction (fig. 6).

In summary, therefore, it appears unlikely that hyperinflation is related directly either to nocturnal asthma or to REM sleep hypoxaemia in patients with COPD. 
a)

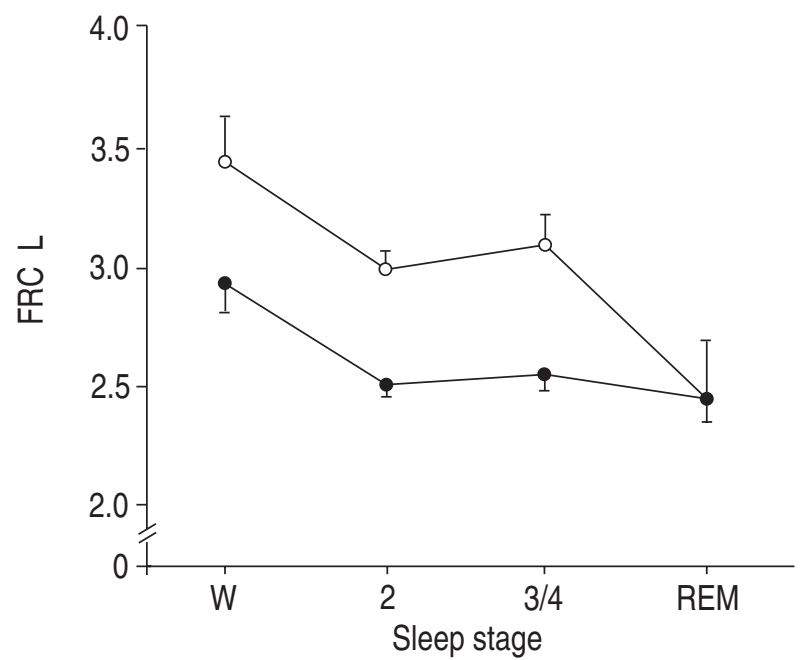

b)

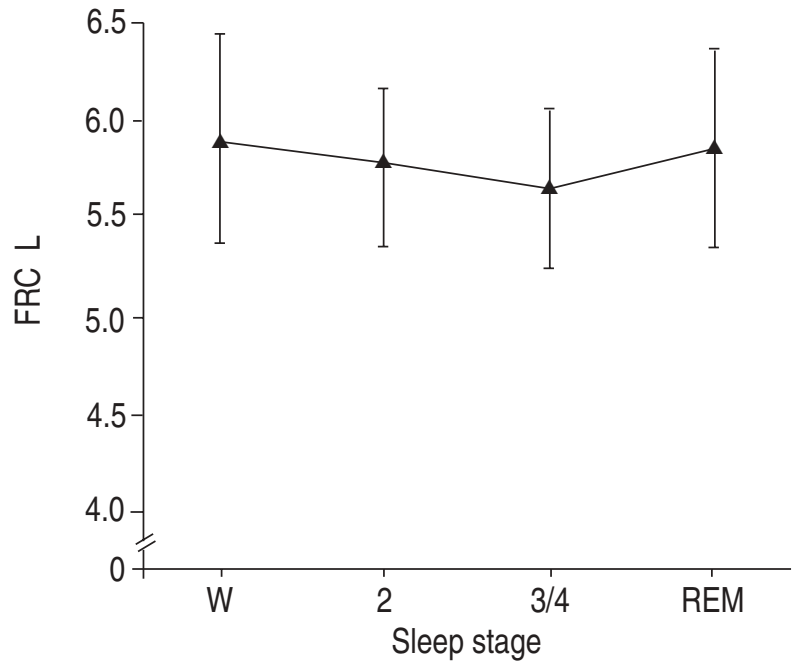

Fig. 5. - Effect of sleep on functional residual capacity (FRC) in: a) asthmatic (O) compared to normal (๑) subjects; b) in patients with COPD (A). Bars indicate SEM. W: awake; 2, 3 and 4: stages 2, 3 and 4 non-rapid eye movement sleep; REM: rapid eye movement sleep. COPD: chronic obstructive pulmonary disease. (Modified from BALLARD and co-workers [48] and [51], respectively).

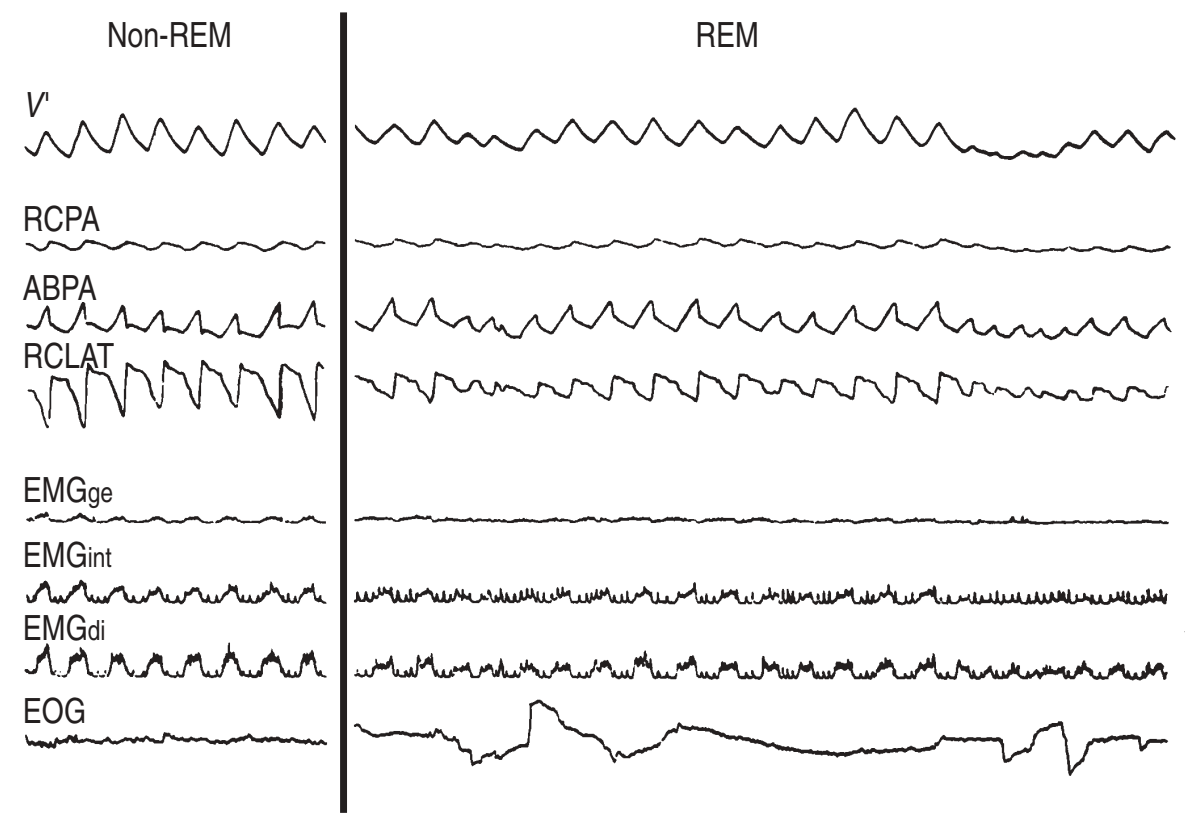

Fig. 6. - Sleep recording from a patient with chronic obstructive pulmonary disease (COPD) and hyperinflation in rapid eye movement (REM) and non-REM sleep. Signals are airflow $\left(V^{\prime}\right)$, posteroanterior diameter of rib cage (RCPA) and abdomen (ABPA), low lateral diameter of rib cage (RCLAT), surface electromyogram (EMG) of upper airway muscles (EMGge), parasternal intercostals (EMGint) and diaphragm (EMGdi) and electo-oculogram (EOG). Note the marked lateral paradox of rib cage (Hoover's sign) in non-REM sleep; this becomes less marked in REM sleep, when activity of all inspiratory muscle groups is suppressed. (Reproduced, with permission, from WHITE et al. [52]).

\section{Breathlessness and exercise performance}

O'Connell and Campbell [53] showed that patients with COPD with inspiratory dyspnoea at rest had greater FRC than those who were not dyspnoeic, but they also had lower values of FEV1. The clearest discriminant between dyspnoeic and nondyspnoeic patients was the ratio of the pressure required to generate tidal flow to that available statically at the same lung volume, i.e. an index of the load/capacity ratio. A similar conclusion was reached by LEBLANC et al. [54] studying patients with various diseases during exercise. They found that one important correlate of the breathlessness score on exercise was the ratio of mean pleural pressure to $P$ I,max, again an index of the load/capacity ratio of the inspiratory muscles, that will depend on the severity of hyperinflation. This factor was independent of other determinants of breathlessness, which included overall ventilation and respiratory frequency.

Several studies [55-60] have shown that, on exercise, the FRC of patients with COPD rises because of increasing dynamic hyperinflation. The residual volume increases similarly, but there appears to be no acute change in TLC [57]. The increase in FRC contrasts with the pattern shown in normal subjects, in whom FRC falls on exercise [56, 59]. In two studies, average increases 
in FRC of 0.63 and $0.32 \mathrm{~L}$ between rest and maximal exercise were reported $[58,60]$. The size of the increase depends on the severity of airway narrowing, but increases can occur even in patients with mild-to-moderate disease [59]. Increasing hyperinflation appears to be a consequence of expiratory flow limitation. In mild asthma, as in healthy subjects, FRC may fall during light exercise, but in heavier exercise it increases again as flow limitation develops [61]. This pattern is similar to that seen in healthy elderly subjects, in whom flow limitation at lower lung volumes can occur during heavy exercise [61]. Clearly, an increase in FRC has the advantage of maintaining expiratory flow, and consequently ventilation, when increases are required on exercise. On the other hand, as discussed above, dynamic hyperinflation has adverse effects on the inspiratory muscles. The implications of dynamic hyperinflation for the severity of breathlessness in patients with COPD are apparent from the work of O'Donnell and WebB [60]. They showed that the increase in breathlessness on maximal exercise was clearly related to the extent of dynamic hyperinflation, as assessed by the rise in FRC and consequent loss of inspiratory reserve volume.

The increase in hyperinflation from rest to exercise can be estimated with reasonable accuracy since the evidence suggests that TLC does not change. The magnitude of dynamic hyperinflation at rest is more difficult
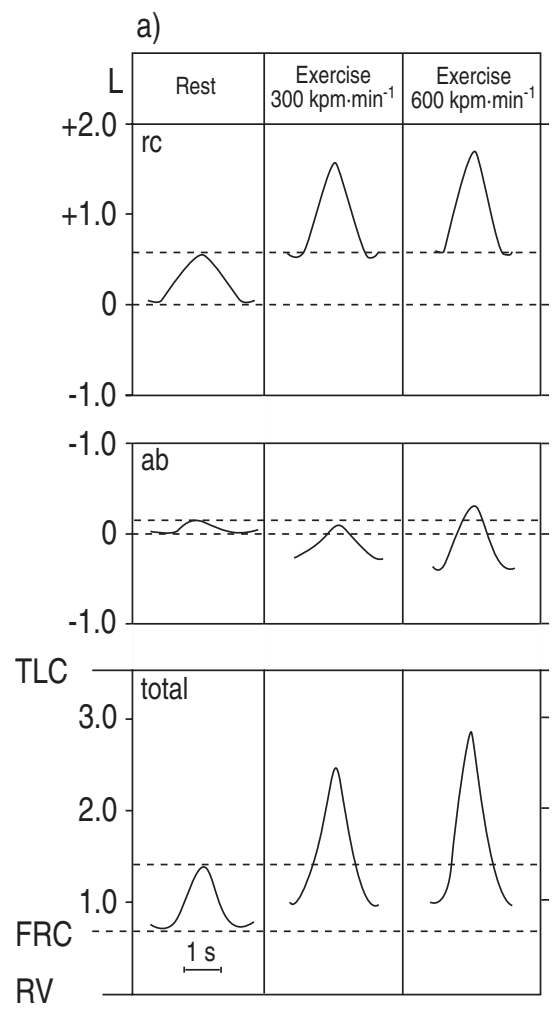

to quantitate directly. By extrapolation of resting tidal expiratory flow curves and calculation of the area under the extrapolated curve, MoRRIs and co-workers [14] estimated the average volume of dynamic hyperinflation in a group of patients with severe COPD to be $0.43 \mathrm{~L}$. In a subsequent study [62], the same authors concluded that the relaxation volume may actually be less than $\mathrm{RV}$. If an additional $0.6 \mathrm{~L}$ or so is added on exercise, the endexpiratory volume may increase to more than a litre above the relaxation volume. In a patient with severe airway obstruction and often greatly reduced vital capacity, such a degree of dynamic hyperinflation severely constrains the tidal volume available on exercise, and consequently the end-inspiratory lung volume may rise to values exceeding $95 \%$ of TLC $[61,63]$.

Although appreciable, the magnitude of the increase in FRC on exercise actually underestimates the severity of hyperinflation of the rib cage compartment (fig. 7). This was first illustrated by the study of GRIMBY et al. [56], who compared the separate motion of the rib cage and abdomen in normal subjects and patients with moderate airway obstruction at rest and on exercise. They showed that the increase in FRC was due entirely to an increase in the end-expiratory volume of the rib cage, while the volume of the abdomen actually decreased. All the increased volume was accommodated within the rib cage, but, in addition, this compartment had
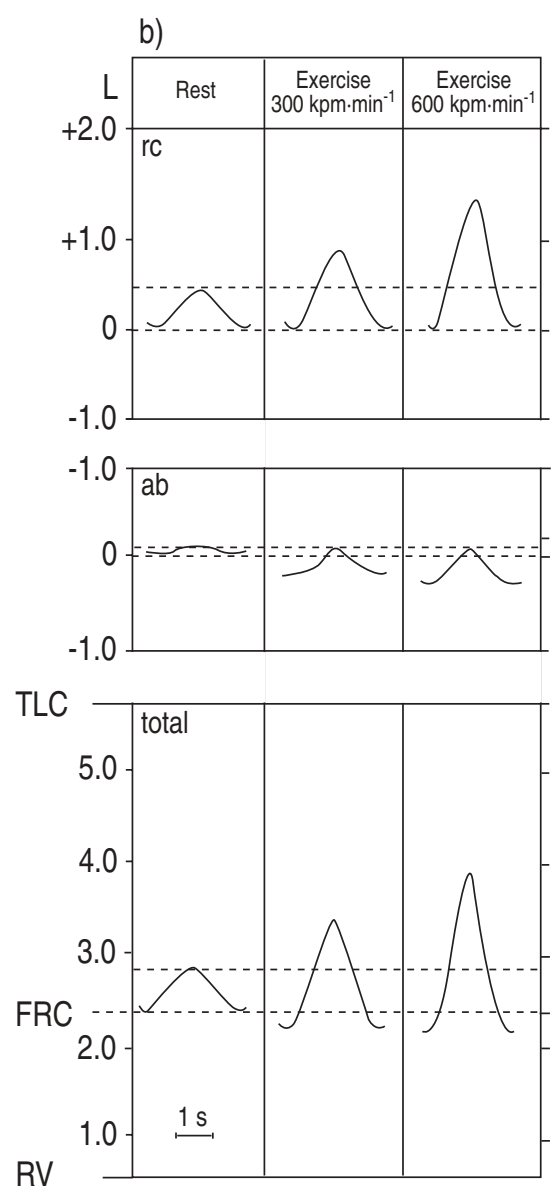

Fig. 7. - Changes in lung (total) and compartmental volumes of rib cage (rc) and abdomen (ab) during exercise: a) in patients with hyperinflation (COPD); and b) in normal subjects. Broken lines indicate end-expiratory (FRC) and end-inspiratory volumes at rest. In the patients with COPD, FRC increased on exercise and abdominal volume decreased such that the rib cage compartment was even more hyperinflated than would be estimated from the changes in overall lung volume. FRC: functional residual capacity; TLC: total lung capacity. (Modified from GRIMBY et al. [56]). 
to compensate for the reduction in abdominal volume. Nevertheless, despite a reduction in its volume, the relative displacement of the abdomen increased on exercise in most subjects. This was in contrast to the situation in normal subjects in whom the relative abdominal displacement on exercise was similar to that at rest. Similar findings were reported by DoDD et al. [58], who confirmed that the relatively greater abdominal displacement on exercise in patients with COPD was all in the expiratory direction. It results from abdominal muscle contraction during expiration, which exerts a "protective" effect on the diaphragm. Thus, although patients may be unable to deflate their lungs on exercise to the resting FRC, the compartmental changes allow diaphragmatic contour and length to be conserved, albeit at the cost of impaired capacity of the rib cage muscles.

In a recent study with important clinical implications, BELMAN et al. [63] studied the responses to exercise of patients with COPD after treatment with either placebo or a bronchodilator (salbutamol). Earlier studies had suggested that the symptomatic response to a bronchodilator might result not only from reversal of airway narrowing but also from relief of hyperinflation. This was, for instance, proposed by WoOLCOCK and READ [27] in their classic study of lung volumes during recovery from spontaneous asthma. Also, MulLer et al. [16] showed that after inhaled salbutamol a reduction in tonic inspiratory muscle activity was accompanied by an average reduction in FRC of $13 \%$. In the study by BELMAN et al. [63], changes in FRC at rest after bronchodilatation were small and not statistically significant, but at the highest workload during progressive exercise both FRC and end-inspiratory lung volume fell significantly more with salbutamol than with placebo. The accompanying reduction in breathlessness correlated most closely with the reduction in dynamic hyperinflation on exercise, as assessed by the fall in end-inspiratory lung volume. On the other hand, reduction in the breathlessness score was unrelated to improvement in spirometric indices or to changes in resting FRC. Therefore, this study clearly has potential implications for the mechanism of symptomatic relief in patients with airway obstruction, perhaps particularly in those with COPD in whom changes in conventional tests of airway function are generally small. The mechanism of improvement is probably a combination of reduced load and improved inspiratory muscle capacity accompanying partial reversal of hyperinflation, i.e. a reduction in the all important load/ capacity ratio, which appears to be a major determinant of breathlessness in patients with airway disease.

Further evidence of the importance of dynamic hyperinflation in the genesis of dyspnoea comes from studies of the possible beneficial effects of continuous positive airway pressure (CPAP) applied externally with the aim of assisting inspiration and balancing the inspiratory threshold load. Beneficial effects in terms both of the calculated inspiratory effort and the severity of breathlessness have been reported in patients with acute exacerbations of COPD during weaning from mechanical ventilation [64], and more recently in similar patients during acute hypercapnic exacerbations breathing spontaneously without ventilatory support [65]. Provided that modest pressures are used, CPAP produces no further increase in FRC [65]. Furthermore, in ambulant patients with stable COPD, CPAP of $4-5 \mathrm{cmH}_{2} \mathrm{O}$ has been shown to reduce dyspnoea during exercise [66], and to increase exercise endurance time [67], again without producing greater dynamic hyperinflation.

CPAP has not proved to be beneficial in all studies of COPD however, [68], and application of pressure during inspiration only (inspiratory pressure support) appears to have more consistent beneficial effects [65, 68 , 69]. Pressure support during inspiration alone assists the inspiratory muscles during airflow, but does not counterbalance the initial effect on the muscles of inspiratory threshold loading, since the patient still needs to generate inspiratory force to overcome this load before developing the flow which triggers the ventilating device to provide assistance. The relative importance of these factors in the genesis of dyspnoea is not clear. Recent data suggest that the response to applied pressure in acutely induced asthma may differ from that which pertains during exercise in patients with stable chronic airway obstruction.

While studies in COPD during exercise have shown that inspiratory pressure support gives more consistent symptomatic relief, a recent study of patients with induced asthma showed that CPAP produced greater symptomatic benefit than pressure during inspiration only [70]. The apparently different responses may be a consequence of persistent inspiratory muscle activity during expiration in asthma, while in COPD dynamic hyperinflation is essentially passive.

The application of positive pressure at the mouth for symptomatic relief during exercise is currently not a practicable proposition for routine treatment, but it might be of value in rehabilitation programmes.

\section{References}

1. Simon G. Principles of Chest X-ray Diagnosis. 3rd edn. London, Butterworths, 1971.

2. Simon G, Pride NB, Jones NL, Raimondi AC. Relation between abnormalities in the chest radiograph and changes in pulmonary function in chronic bronchitis and emphysema. Thorax 1973; 28: 15-23.

3. Pierce JA, Ebert RV. The barrel deformity of the chest, the senile lung and obstructive pulmonary emphysema. Am J Med 1958; 25: 13-22.

4. Kilburn KH, Asmundsson T. Anteroposterior chest diameter in emphysema. Arch Intern Med 1969; 123: 379-382.

5. Gilmartin JJ, Gibson GJ. Abnormalities of chest wall motion in patients with chronic airflow obstruction. Thorax 1984; 39: 264-271.

6. Burki NK, Krumpelman JL. Correlation of pulmonary function with the chest roentgenogram in chronic airway obstruction. Am Rev Respir Dis 1980; 121: 217223.

7. Sharp JT, Beard GAT, Sunga M, et al. The rib cage in normal and emphysematous subjects: a roentgenographic approach. J Appl Physiol 1986; 61: 2050-2059.

8. Walsh JM, Webber CL, Fahey PJ, Sharp JT. Structural change of the thorax in chronic obstructive pulmonary disease. J Appl Physiol 1992; 72: 1270-1278.

9. Ringel ER, Loring SH, McFadden ER, Ingram RH. Chest wall configurational changes before and during acute obstructive episodes in asthma. Am Rev Respir Dis 1983; 128: 607-610. 
10. Hoover CF. The diagnostic significance of inspiratory movements of the costal margins. Am J Med Sci 1920; 159: 633-646.

11. Gilmartin JJ, Gibson GJ. Mechanisms of paradoxical rib cage motion in patients with chronic obstructive pulmonary disease. Am Rev Respir Dis 1986; 134: 683687.

12. Sharp JT, Goldberg NB, Druz WS, Fishman HC, Danon J. Thoracoabdominal motion in chronic obstructive pulmonary disease. Am Rev Respir Dis 1977; 115: 47-56.

13. Citterio G, Agostoni E, Del Santo A, Marazzini L. Decay of inspiratory muscle activity in chronic airway obstruction. J Appl Physiol: Respirat Environ Exercise Physiol 1981; 51: 1388-1397.

14. Morris MJ, Madgwick RG, Frew AJ, Lane DJ. Breathing muscle activity during expiration in patients with chronic airflow obstruction. Eur Respir J 1990; 3: 901909.

15. Martin J, Howell E, Shore S, Emrich J, Engel LA. The role of respiratory muscles in the hyperinflation of bronchial asthma. Am Rev Respir Dis 1980; 121: 441447.

16. Muller N, Bryan AC, Zamel N. Tonic inspiratory muscle activity as a cause of hyperinflation in asthma. $J$ Appl Physiol: Respirat Environ Exercise Physiol 1981; 50: 279-282.

17. Sharp JT, Van Lith P, Nuchprayoon CV, Briney R, Johnson FN. The thorax in chronic obstructive lung disease. Am J Med 1968; 44: 30-46.

18. Byrd RB, Hyatt RE. Maximal respiratory pressures in chronic obstructive lung disease. Am Rev Respir Dis 1968; 98: 848-856.

19. Rochester DF, Arora NS, Braun MT, Goldberg SK. The respiratory muscles in chronic obstructive pulmonary disease (COPD). Bull Eur Physiopathol Respir 1979; 15: 951-975.

20. Gibson GJ, Clark E, Pride NB. Static transdiaphragmatic pressures in normal subjects and in patients with chronic hyperinflation. Am Rev Respir Dis 1981; 124: 685-689.

21. Similowski T, Yan S, Gauthier A, et al. Contractile properties of the human diaphragm during chronic hyperinflation. N Engl J Med 1991; 325: 917-923.

22. De Troyer A. Eur Respir J, In Press.

23. Burrows B, Strauss RH, Niden AH. Chronic obstructive lung disease. III. Interrelationships of pulmonary function data. Am Rev Respir Dis 1965; 91: 861-868.

24. Begin P, Grassino A. Inspiratory muscle dysfunction in chronic hypercapnia in chronic obstructive pulmonary disease. Am Rev Respir Dis 1991; 143: 905-912.

25. Hodson ME, Simon G, Batten JC. Radiology of uncomplicated asthma. Thorax 1974; 29: 296-303.

26. Merkus PJFM, Van Essen-Zandvliet EEM, Kouwenberg $\mathrm{JM}$, et al. Large lungs after childhood asthma: a case control study. Am Rev Respir Dis 1993; 148: 1484-1489.

27. Woolcock AJ, Read J. Lung volumes in exacerbations of asthma. Am J Med 1966; 41: 259-273.

28. Woolcock AJ, Rebuck AS, Cade JF, Read J. Lung volume changes in asthma measured concurrently by two methods. Am Rev Respir Dis 1971; 104: 703-709.

29. Anderson SD, McEvoy JDS, Bianco S. Changes in lung volumes and airway resistance after exercise in asthmatic subjects. Am Rev Respir Dis 1972; 106: 30-37.

30. Freedman S, Tattersfield AE, Pride NB. Changes in lung mechanics during asthma induced by exercise. $J$ Appl Physiol 1975; 38: 974-982.

31. Stanescu DC, Frans S, Brasseur L. Acute increase of total lung capacity in asthma following histamine aerosols. Bull Eur Physiopathol Respir 1973; 9: 523-530.

32. Rodenstein DO, Stanescu DC. Reassessment of lung volume measurement by helium dilution and by body plethysmography in chronic airflow obstruction. Am Rev Respir Dis 1982; 126: 1040-1044.

33. Stanescu DC, Rodenstein D, Camberghs M, van de Woestijne KP. Failure of body plethysmography in bronchial asthma. J Appl Physiol: Respirat Environ Exercise Physiol 1982; 52: 939-948.

34. Shore SA, Huk O, Mannix S, Martin JG. Effect of panting frequency on the plethysmographic determination of thoracic gas volume in chronic obstructive pulmonary disease. Am Rev Respir Dis 1983; 128: 54-59.

35. Rothstein MS, Zilefsky MN, Eichacker PQ, Rudolph DJ, Williams MH. Radiographic measurement of total lung capacity in acute asthma. Thorax 1989; 44: 510512 .

36. Blackie SP, Al-Majed S, Staples CA, Hilliam C, Paré PD. Changes in total lung capacity during acute spontaneous asthma. Am Rev Respir Dis 1990; 142: 79-83.

37. Kirby JG, Juniper EF, Hargreave FE, Zamel N. Total lung capacity does not change during methacholinestimulated airway narrowing. J Appl Physiol 1986; 61: 2144-2147.

38. Lougheed MD, Lam M, Forkert L, Webb KA, O'Donnell DE. Breathlessness during acute bronchoconstriction in asthma: pathophysiologic mechanisms. Am Rev Respir Dis 1993; 148: 1452-1459.

39. Landau LI, Phelan PD, Williams HE. Ventilatory mechanics in patients with bronchiectasis starting in childhood. Thorax 1974; 29: 304-312.

40. Landau LI, Phelan PD. The spectrum of cystic fibrosis. Am Rev Respir Dis 1973; 108: 593-602.

41. Marks J, Pasterkamp H, Tal A, Leahy F. Relationship between respiratory muscle strength, nutritional status and lung volume in cystic fibrosis and asthma. Am Rev Respir Dis 1986; 133: 414-417.

42. Szeinberg A, England S, Lindorff C, Fraser IM, Levison $\mathrm{H}$. Maximal inspiratory and expiratory pressures are reduced in hyperinflated malnourished young adult male patients with cystic fibrosis. Am Rev Respir Dis 1985; 132: 766-769.

43. Donahoe M, Rogers RM, Wilson DO, Pennock BE. Oxygen consumption of the respiratory muscles in normal and in malnourished patients with chronic obstructive pulmonary disease. Am Rev Respir Dis 1989; 140: 385391.

44. Pitcher WD, Cunningham HS. Oxygen cost of increasing tidal volume and diaphragm flattening in obstructive pulmonary disease. J Appl Physiol 1993; 74: 2750-2756.

45. Fitting JW, Frascarolo P, Jequier E, Leuenberger P. Energy expenditure in rib cage: abdominal motion in chronic obstructive pulmonary disease. Eur Respir $J$ 1989; 2: 840-845.

46. Rochester DF, Braun NMT. Determinants of maximal inspiratory pressure in chronic obstructive pulmonary disease. Am Rev Respir Dis 1985; 132: 42-47.

47. Haluszka J, Chartrand DA, Grassino AE, Milic-Emili J. Intrinsic PEEP and arterial $\mathrm{PCO}_{2}$ in stable patients with chronic obstructive pulmonary disease. Am Rev Respir Dis 1990; 141: 1194-1197.

48. Ballard RD, Irvin CG, Martin RJ, Pak J, Pandey R, White DP. Influence of sleep on lung volume in asthmatic patients and normal subjects. J Appl Physiol 1990; 68: 2034-2041. 
49. Martin RJ, Pak J, Irvin CG. Effect of lung volume maintenance during sleep in nocturnal asthma. J Appl Physiol 1993; 75: 1467-1470.

50. Ballard RD, Clover CW, White DP. Influence of nonREM sleep on inspiratory muscle activity in lung volume in asthmatic patients. Am Rev Respir Dis 1993; 147: 880-886.

51. Ballard RD, Clover CW, Suh BY. Influence of sleep on respiratory function in emphysema. Am J Respir Crit Care Med 1995; 151: 945-951.

52. White JES, Drinnan MJ, Smithson AJ, Griffiths CJ, Gibson GJ. Respiratory muscle activity during rapid eye movement (REM) sleep in patients with chronic obstructive pulmonary disease. Thorax 1995; 50: 376-382.

53. O'Connell JM, Campbell AH. Respiratory mechanics in airways obstruction associated with inspiratory dyspnoea. Thorax 1976; 31: 669-677.

54. Leblanc P, Bowie DM, Summers E, Jones NL, Killian KJ. Breathlessness and exercise in patients with cardiorespiratory disease. Am Rev Respir Dis 1986; 133: 21-25.

55. Potter WA, Olafsson S, Hyatt RE. Ventilatory mechanics and expiratory flow limitation during exercise in patients with obstructive lung disease. J Clin Invest 1971; 50: 901-909.

56. Grimby G, Elgefors V, Oxhoj H. Ventilatory levels in chest wall mechanics during exercise in obstructive lung disease. Scand J Respir Dis 1973; 54: 45-52.

57. Stubbing DG, Pengelly LD, Morse JLC, Jones NL. Pulmonary mechanics during exercise in subjects with chronic airflow obstruction. J Appl Physiol 1980; 49: 511-515.

58. Dodd DS, Brancatisano T, Engel LA. Chest wall mechanics during exercise in patients with severe chronic airflow obstruction. Am Rev Respir Dis 1984; 129: 33-38.

59. Babb TG, Viggiano R, Hurley B, Staats B, Rodarte JR. The effect of mild-moderate airflow limitation on exercise capacity. J Appl Physiol 1991; 70: 223-230.

60. O'Donnell DE, Webb KA. Exertional breathlessness in patients with chronic airflow limitation: the role of lung hyperinflation. Am Rev Respir Dis 1993; 148: 1351-1357.
61. Johnson BD, Scanlon GD, Beck KC. Regulation of ventilatory capacity during exercise in asthmatics. $J$ Appl Physiol 1995; 79: 892-901.

62. Morris MJ, Madgwick RG, Lane DJ. Difference between functional residual capacity and elastic equilibrium volume in patients with chronic obstructive pulmonary disease. Thorax 1996; 51: 415-419.

63. Belman MJ, Botnick WC, Shin JW. Inhaled bronchodilators reduce dynamic hyperinflation during exercise in patients with chronic obstructive pulmonary disease. Am J Respir Crit Care Med 1996; 153: 967-975.

64. Petrof JB, Legare M, Goldberg P, Milic-Emili J, Gottfried SB. Continuous positive airway pressure reduces work of breathing and dyspnoea during weaning from mechanical ventilation in severe chronic obstructive disease. Am Rev Respir Dis 1990; 141: 281-289.

65. Goldberg P, Reissmann H, Maltais F, Ranieri M, Gottfried SB. Efficacy of noninvasive CPAP in COPD with acute respiratory failure. Eur Respir J 1995; 8: 1894-1900.

66. O'Donnell DE, Sanii R, Gisberecht G, Younes M. Effect of continuous positive airway pressure on respiratory sensation in patients with chronic obstructive pulmonary disease during submaximal exercise. Am Rev Respir Dis 1988; 138: 1185-1191.

67. O'Donnell DE, Sanii R, Younes M. Improvement in exercise endurance in patients with chronic airflow limitation using continuous positive airway pressure. Am Rev Respir Dis 1988; 138: 1510-1514.

68. Keilty SEJ, Ponte J, Fleming TA, Moxham J. Effect of inspiratory pressure support on exercise tolerance and breathlessness in patients with severe stable chronic obstructive pulmonary disease. Thorax 1994; 49: 990 994.

69. Maltais F, Reissmann H, Gottfreid SB. Pressure support reduces inspiratory effort and dyspnoea during exercise in chronic airflow obstruction. Am J Respir Crit Care Med 1995; 151: 1027-1033.

70. Lougheed MD, Webb KA, O'Donnell DE. Breathlessness during induced lung hyperinflation in asthma: the role of the inspiratory threshold load. Am J Respir Crit Care Med 1995; 152: 911-920. 